JELTL (Journal of English Language Teaching and Linguistics) e-ISSN: 2502-6062, p-ISSN: 2503-1848

2018, Vol. 3 (2)

www.jeltl.org

\title{
The Rise of Misinformation in the Digital Age: Moroccan Students' Attitudes and Perceptions of Fake News Online
}

\author{
Isam Mrah \\ Regional Center of Education and Training, Morocco \\ E-mail :mrahissam@gmail.com \\ Hicham Tizaoui \\ Regional Center of Education and Training, Morocco \\ E-mail : hichamtizaoui@gmail.com
}

\begin{abstract}
As today's students spend substantial time online, there is an increasing tendency to utilize the Internet as their primary source of information. With the proliferation of user-generated content platforms and the shrinking influence of traditional gatekeeping, there is a growing abundance of misinformation available to the public that coexists alongside accurate information. In this paper, we explored the attitudes and perceptions of teenage students towards misinformation online. To this end, a web-based survey was administered to both Moroccan high school teachers and students to collect and analyze their responses regarding the issue being debated. Additionally, the present study investigated the extent to which EFL textbooks in Morocco enable learners to build skills necessary for identifying fake news. The study adopted content analysis as the primary research method for data analysis and interpretation. The results obtained are in line with the hypothesis guiding this research that a fair majority of teenage students are vulnerable to misinformation online due in large to the overwhelming information overload available at the touch of a button along with their lack of exposure to effective strategies for processing information online. Based on the findings obtained, schools are required to develop appropriate approaches to teach digital literacy skills, particularly in empowering young learners to distinguish credible sources from unreliable ones. Equally important, teachers are called upon to help students keep up with the new, fastmoving knowledge economy, which is driven by information and technology.

Keywords: Misinformation, Teenage Students, Critical Thinking, User-generated Content
\end{abstract}




\section{INTRODUCTION}

In this age of information technology, individuals are constantly receiving a substantial amount of information from various sources in a way that makes it compelling to process online content through critical eyes. The same holds true for teenage students who are exposed to a wide range of information available at the click of a mouse. The massive diffusion of user-generated content has redefined information-sharing boundaries, turning digital natives from consumers to producers of knowledge (Mrah, 2017).

Web 2.0 has radically redefined the dynamics of information exchange. As breaking news unfolds, people increasingly turn to social media to stay abreast of the latest updates. The term fake news continues to dominate headlines as the volume of fabricated news stories circulating on social media increases (Orlando, 2017). Recent research has shown that young people obtain a substantial amount of their news from social media feeds (Orlando, 2017). Fabricated stories as an emerging form of journalism potentially influence public opinion. Platforms like Twitter and Facebook act as a megaphone to attract followers, irrespective of message content (Orlando, 2017). Being able to verify the trustworthiness of information is an increasing concern for parents and educators.

Oxford dictionaries named "post-truth" as the word of the year, defining it as "relating to circumstances in which people respond more to feelings and beliefs than to facts" (Cited in Anderson \& Rainie, 2017). The 2016 Brexit referendum in the United Kingdom and the controversial U.S. presidential election are a telling example of how the digital age has impacted news media and cultural narratives (Anderson \& Rainie, 2017). The information we access and consume online is critical to forming our perceptions of the world around us.

\subsection{Statement of the Problem}

Despite widespread research on social media usage, little is known about the rise of fabricated news stories, websites and other forms of misinformation intended to manipulate public opinion. Against this background, the present study draws the attention of EFL practitioners to the growing concern attributed to the prevalence of online misinformation among students. The primary objective of this paper is to determine the key variables that affect how Moroccan high school students interpret or decode information circulating online. Developing students' evaluative and reflective skills are not given due consideration in Moroccan schools. The increasing use of social media for information sharing calls upon the need for information literacy education to better prepare students to effectively process information.

\subsection{Purpose and Significance of the Study}

This research set out to explore the interplay between social media usage and digital media content distribution. With the alarming rise in fake news, there is a pressing need for more research on the dynamics of misinformation in the age of digital media. Given that unsubstantiated information has the potential to affect 
behavior on a massive scale, it is critical to understand how it operates and how to mitigate its harmful effects.

The motivation to conduct this study arises from the literature gap on the usage of social media for the circulation of misinformation among students. Much of the research on social media has focused on the democratizing potential of the new media, with little investigation into how users consume information online. The limited literature on this issue is a compelling justification to undertake this research. This case study provides a unique opportunity to enhance our understanding of social media usage and to gain a wider perspective on the dynamics of digital media consumption. With the explosion of fake news infiltrating social media, there is an urgent need to broaden the focus of research on misinformation.

\subsection{Research Question and Hypothesis}

The advent of Web 2.0 has reinvented journalism practice, allowing users unprecedented opportunities to interact and connect with media content. This study is motivated by the curiosity to investigate the attitudes of users towards online content and identify the strategies adopted for obtaining and evaluating information. To this end, the primary research question guiding this study was: What are students' perceptions and attitudes towards digital media content? The central hypothesis guiding this research is that Moroccan high school students lack basic training and skills to tell the difference between information and misinformation.

\subsection{Limitations of the Study}

The most important limitation to this study might be the relatively small sample size of the survey takers which may not be considered representative of the larger population. Additionally, the extensive use of close-ended questions may limit response options given that most of the response formats provided in the questionnaire are dichotomous.

\section{LITERATURE REVIEW}

The purpose of this section is to review and synthesize existing literature on misinformation online along with outlining the background to the research.

Fake news comprises information deliberately made available for public consumption and media distribution to create a false impression or mislead the public (Burgoon, Buller, Guerrero, Afifi, \& Feldman, 1996). This form of deception involves the careful construction of messages or stories and the intentional manipulation of public opinion to evoke a sense of veracity (Zhou \& Zhang, 2008).

Studies have shown that emotionally charged narratives tend to be far more memorable than neutral content (Cahill \& McGaugh, 1995; Lewandowsky, Ecker, Seifert, Schwarz, \& Cook, 2012; Berger, 2011). Additionally, recent empirical evidence has indicated that emotionally evocative content increases its likelihood to go more viral than neutral content (Berger \& Milkman, 2012). Fake news appeals to the emotions of its readers, tapping into events or themes that affect people on an individual level or have local impact (Southwell, Thorson \& Sheble, 2018). 
Recent scholarship on mass media effects has explored the interplay between unverified news and digital literacy. Recently published works have demonstrated that the increasing exposure of users to unsubstantiated rumors increases their likelihood to be credulous (Bessi, Scala, Rossi, Zhang \& Quattrociochi, 2016). A news item is accepted as valid by how much it coheres with the user's system of beliefs (Dong XL, et al., 2015). In most cases, the information is taken by a friend having the same profile, resulting in the formation of "homogeneous, polarized clusters" (Bessi et al., 2016).

A new study has found that an alarming number of young people show blind trust in what they read online as they do not fact check what they see. This makes them "susceptible to being duped" (Skurski et al., 2017). As the internet is a relatively fertile ground for the free exchange of ideas, it will be very hard to regulate the flow of unverified news stories. There are some people who are "not uninformed, but rather misinformed" (Skurski et al., 2017).

Fake news stories cover a wide range of subjects, from unproven cancer cures to celebrity hoaxes and political stories. The latter have drawn special attention in terms of their chances of influencing public perceptions. Unverified fake news stories " can be quicker to go viral than news stories from traditional sources. That's because they were created for sharing - they are clickable, often inflammatory and pander to emotional responses" (Facebook, 2016).

Stanford researchers found that students from middle school to college are faced with mounting difficulties in evaluating the credibility of information (Stanford History Education Group, 2016). The findings suggest that students "had a hard time distinguishing advertisements from news articles or identifying where information came from" (SHEG, 2016). According to Professor Sam Wineburg, the lead author of the Stanford report, many people assume that "because young people are fluent in social media they are equally perceptive about what they find there. Our work shows the opposite to be true" (SHEG, 2016). Among the important findings reported is that students tend to focus more on the content of social media posts than on their sources.

More recently, Facebook has announced new measures to clamp down on the spread of unverified news. The influential social network is in a constant fight to sort verified news reports from made-up stories through partnering with outside factcheckers. In an attempt to restrain the spread of misinformation, fake stories will be publicly "flagged as 'disputed' by third-party fact-checkers, forcing them to appear lower down in people's news feed." (Facebook, 2016). According to the Common Core State Standards (CCSS), evidence-based reasoning is "essential to both private deliberation and responsible citizenship in a democratic republic" (National Governors Association Center for Best Practices \& Council of Chief State School Officers, 2010, p. 3).

With the availability of internet-mediated platforms, online users tend to seek information that generally aligns with their views and perspectives. Alternatively, there is a tendency among users to downplay, ignore or even dismiss conflicting information and evidence. Acts of dissonance are manifested in joining polarized groups where they end up reinforcing their worldview (Schmidta et al, 2017). Such 
political polarization exacerbates the tendency for "like-minded people to group together, thus creating echo chambers wherein similar opinions circulate repeatedly, leading to the reinforcement of existing opinions and the fragmentation of speech communities" (Takikawa \& Nagayoshi, 2017).

A 2016 survey by the Pew Research Center showed that 23 percent of U.S. adults have shared fake news, knowingly or unknowingly, with friends and acquaintances. With the availability of new information platforms, people tend to align themselves with like-minded individuals. A similar study that examined Facebook users' interactions with news outlets found that online users have a tendency to seek information that conforms to their views (Anderson \& Rainie, 2017).

According to a Stanford University study of 7,804 students from middle school through college, 82 percent of middle-schoolers "could not distinguish between an ad labeled 'sponsored content' and a real news story on a website" (Shellenbarger, 2016). The most compelling finding is that school teens have a tendency to take social media news at face value without considering the source. Many students judged the credibility of news content and narratives depending on how much detail they contained rather than on the source from which the information is derived (Shellenbarger, 2016).

In a study undertaken by Bartlett and Miller (2011), a specific body of skills is required to make informed judgments. They employed the term "digital fluency" to describe the "ability to find and critically evaluate online information. It is a combination of old critical thinking skills, such as source verification, and new knowledge about how the digital world works, such as understanding sear engines" (Bartlett \& Miller, 2011). The study showed that "digital natives"(12-18 years olds) are very confident users of the internet, but not particularly competent. This digital incompetence involves failure to apply checks on the information accessed by young learners.

While much has been written about misinformation among social media users, a limited amount of peer-reviewed research has been published on the perceptions and impact of misinformation on school students. This literature review contributes to the existing scholarship on media studies in an attempt to deepen our understanding of the misinformation ecosystem. Further research is warranted to explore the implications of the massive digital misinformation for the online community in general and students in particular.

\section{RESEARCH METHODS}

The present study had as a purpose (a) to obtain an overview of students' use of social media for school purposes and (b) to explore their attitudes towards social media as a source of information for school work. To this end, two web based surveys were administered to collect quantitative and qualitative data from both Moroccan high school teachers and students with a representative sample size of 120 , combining both multiple choice items and close and open-ended questions. Surveys are a useful research tool for gathering a great deal of information from a larger population. The analysis performed was both descriptive and inferential. 
Responses were summarized into counts of how many occurrences there were for each response. Following descriptive statistics analysis, inferential statistical analysis was conducted to interpret the data generated and test the research hypothesis.

\subsection{Online Survey for Teachers}

The web-based survey administered to Moroccan high school teachers (Appendix A) consisted of three sections covering a total of 19 questions: (a) Respondent profile, (b) Teachers ' attitudes towards online media content, and (c) How and for what purposes social media platforms are utilized among teachers. The opening page contained the informed consent form. The online survey included a variety of question formats, ranging from multiple choice (single or multiple questions), self-assessment items, close-ended questions, likert scale to open-ended questions.

The survey was created using Goolge Forms to both collect online data and perform a statistical analysis. It was made publically available through an URL that was posted on various social networking platforms to obtain a representative sample of the population. The questionnaire was administered both in Arabic and English to ensure maximum response rates.

\subsection{Online Survey for Students}

To gauge how students process and retain information online, a web-based survey was administered to Moroccan high school students (See Apendix B). The survey consisted of three sections covering a total of 21 questions: (a) Respondent profile, (b) Students ' attitudes towards online media content, and (c) How and for what purposes social media platforms are utilized among students. The online survey contained a variety of question formats, ranging from multiple choice items, self-assessment items, close-ended questions, likert scale to open-ended questions.

\section{RESULTS}

This section presents the findings of data analysis of the web-based surveys administered to high school teachers and students to gauge their attitudes and practices towards misinformation. A mixed method approach was utilized to analyze the data obtained and to generate representative and reliable results.

\subsection{Online Survey for Teachers}

Section A was designed to obtain information on respondents' gender, age, teaching experience, and social media usage. Gender was equally distributed with $(50 \%)$ male and $(50 \%)$ female respondents. Half of the surveyed teachers $(50 \%)$ fell in the age group of (20-29) whereas (22\%) percent were aged 30- 39 with a mean age of 28.35. This is indicative that the majority of the survey takers came from young age group. More than half of the respondents $(60 \%)$ had between 5 and 10 years of professional teaching experience.

Drawing on results from the online survey, social media was an important but not a dominant source of news for the respondents, with $29.4 \%$ of teachers 
nominating facebook as the most credible source of news and information. A large percentage of the respondents $(64 \%)$ spent between two to four hours a day on social networking sites. The greatest percentage of the survey takers $(88.2 \%)$ reported that they have never received any training in how to develop students' digital and information literacy skills.

The questions in section B intended to investigate participants' attitudes towards online media content. Half of the surveyed teachers (50\%) indicated their disagreement with the statement that "social networking sites are a credible source of information." As for the open-ended question of how to gauge the veracity of information circulating over the internet, the majority of the respondents reported that they often check other sources to see if what they read online is true. Others indicated that the more a news post is re-shared or retweeted, the more credibility it has. Over half of the participants (53\%) agreed that misinformation is liable to impact students' perception of reality and that emotionally loaded content affects logical reasoning to a large extent $(62 \%)$.

The last section (C) of the survey, which consisted of seven questions, aimed to obtain respondents' perspectives on how and for what purposes social media platforms are utilized. The survey takers were asked to identify main reasons for using social media. The greatest percentage $(80 \%)$ reported that they used social media for socializing with friends and relatives, followed by gathering information on educational related issues (58\%), and entertaining and be entertained (55\%). When asked whether they followed news provided by amateur/citizen journalists, professional journalists, or both, the greatest percentage of respondents $(70.6 \%)$ reported that they followed news provided by both professional and citizen journalists.

To identify how users evaluate the content of articles published online, the survey respondents were asked to select the strategies they most often used to obtain valid information (Figure 1). $81.8 \%$ said that they checked that the author was real and credible, $36.6 \%$ made sure that there was a valid date on the article, and $33.3 \%$ verified that the story supported the headline. Correspondingly, the vast majority of the participants $(76,5 \%)$ underscored the necessity of identifying the source from which the news was taken while reading the news online.

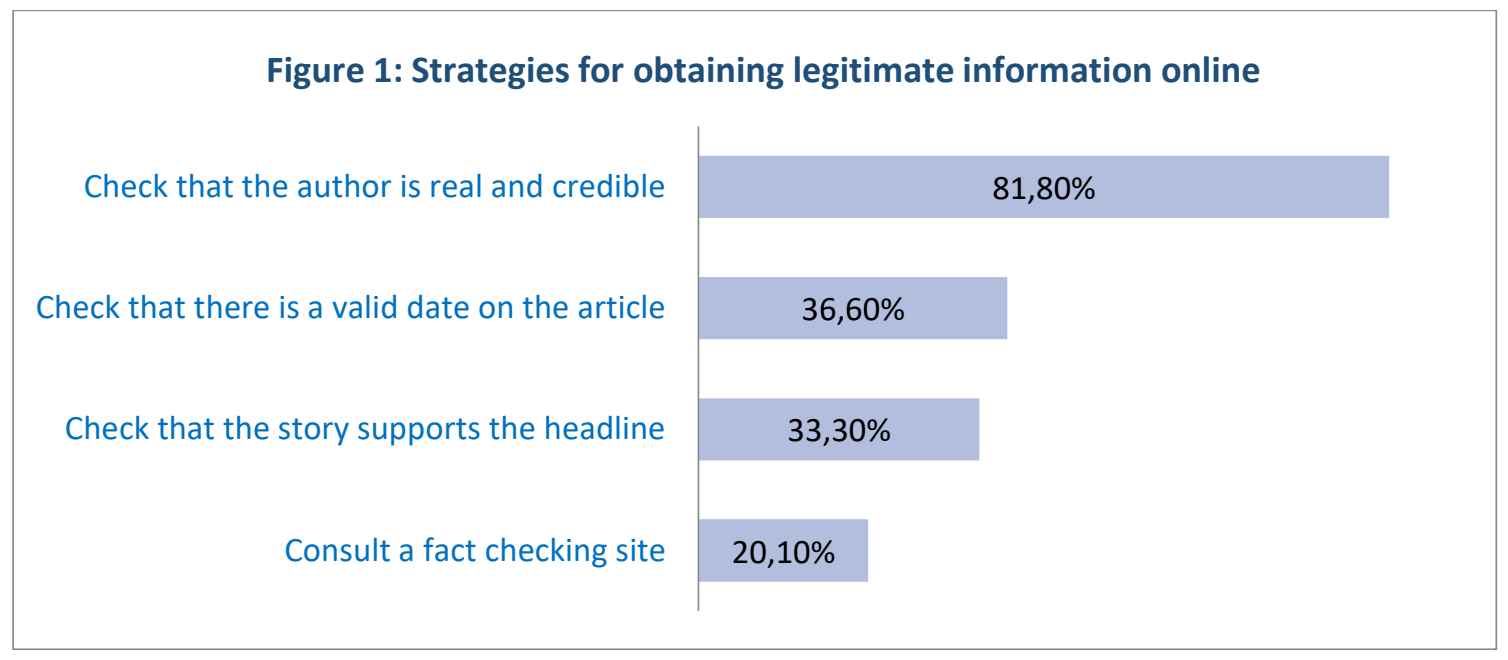

JELTL (Journal of English Language Teaching and Linguistics), 3(2), 2018 
Almost half of the survey takers (45\%) opined that students could not tell the difference between fact and opinion and that they used wiki sites for classroom assignments. As for users' attitudes towards information sharing, $41.20 \%$ of the respondents revealed that they shared news content that aligned with their views, $40 \%$ did not share content online, and $32.40 \%$ only shared content after assessing its veracity (Figure 2).

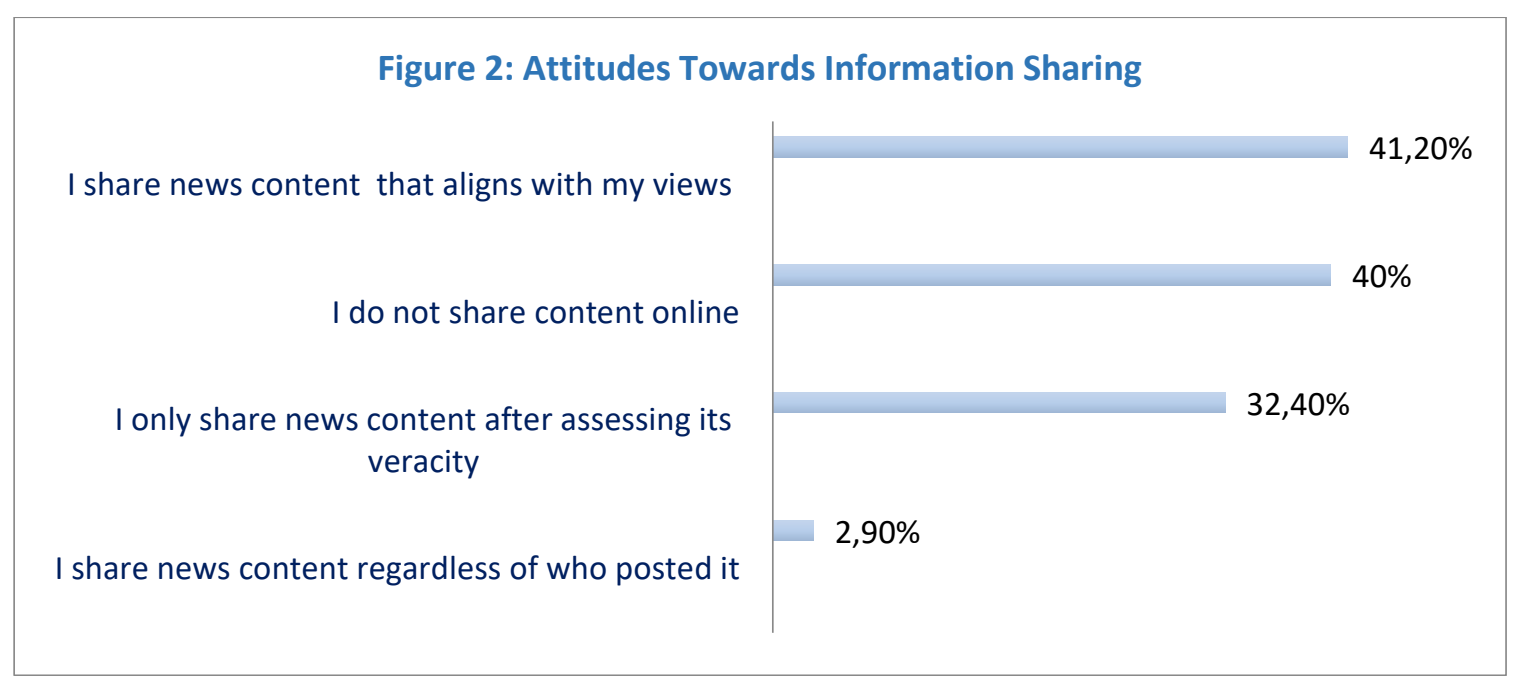

The last question of the questionnaire asked the participants to rate the extent to which EFL coursebooks currently adopted in Moroccan high schools helped develop students' digital and information literacy skills. About half of the respondents $(47.1 \%)$ indicated that the coursebooks did not at all contain activities aimed at developing digital literacy. When asked whether they devised learning activities or tasks that integrated digital literacy competences, the vast majority of the survey takers never or rarely did.

\subsection{Online Survey for Students}

Section A was designed to obtain information on respondents' gender, age, and social media usage. Participants' gender was evenly distributed with $51 \%$ males and $49 \%$ females. More than two thirds of the surveyed students (67\%) fell in the age group of (16-17). The greatest percentage of students (71\%) spent an average of three to four hours a day on social networking sites. Facebook was ranked as the most-used social media platform among students with $65 \%$, followed by Whatapp with $31 \%$. The overwhelming majority $(88 \%)$ reported that they have not received any training in digital and information literacy skills.

The questions in section B intended to investigate participants' attitudes towards online media content. More than two thirds of the survey takers $(68 \%)$ ranked social networking sites as the most credible sources of information, followed by online news sites with $28 \%$. To find out what strategies students employed to know if what they read online was true, the open-ended question remained unanswered. The overwhelming majority of the participants $(71 \%)$ indicated that misinformation has the potential to strongly impact people's perception of reality 
and that the underlying cause behind unsubstantiated information is information overload.

The last section (C) of the survey, which consisted of ten questions, aimed to obtain respondents' perspectives on how and for what purposes social media platforms were utilized. The surveyed students were asked to identify main reasons for using social media. Socializing with friends and relatives topped the list of reasons why users turned to social media $(77 \%)$, followed by seeking and gathering information (54\%). When asked to gauge the importance of truthfulness when sharing information on social media, three quarters $(74.5 \%)$ of the respondents reported that truthfulness was of little importance to them. As for the strategies employed for obtaining valid information from an online article, half of the participants indicated that they did not employ any strategy to check the veracity of information (Figure 3).

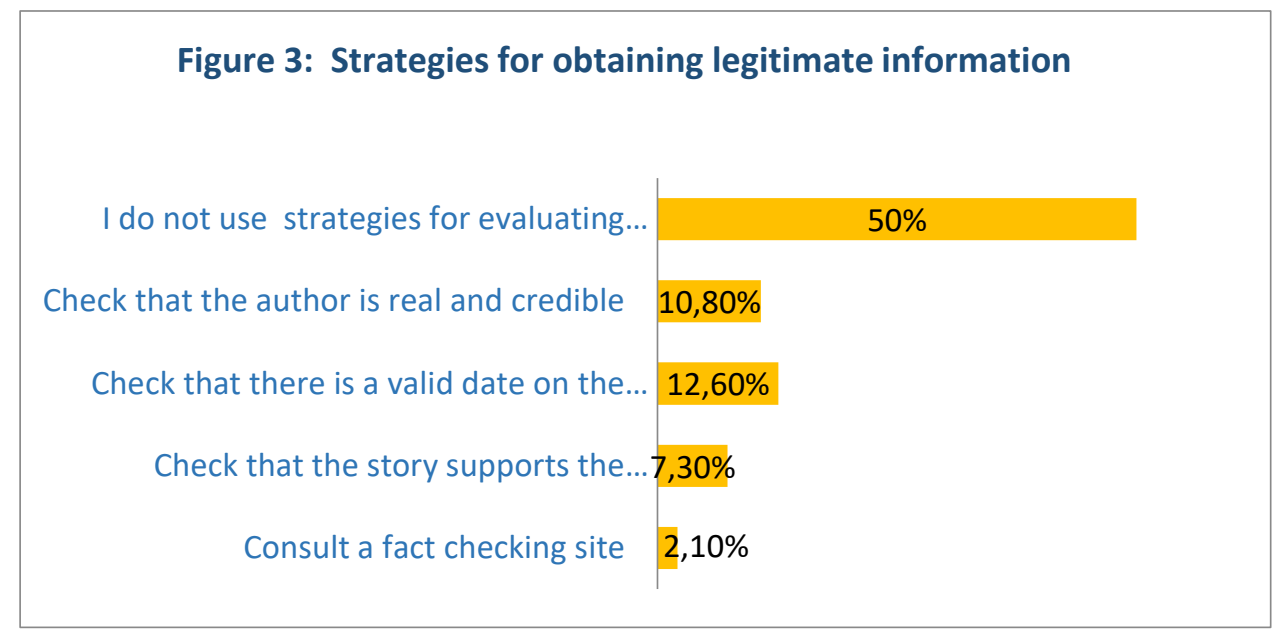

Additionally, more than $60 \%$ of the surveyed students showed indifference towards identifying the source from which the news was taken and expressed their inability to tell the difference between fact and opinion. Almost the same percentage of participants used Wikipedia for classroom assignments and school related work. As for users' attitudes towards information sharing, half of the survey takers reported sharing news content regardless of who posted it while less than $10 \%$ shared content after assessing its veracity (Figure 4). When searching for information online, the overwhelming majority of the surveyed students $(77 \%)$ contented themselves with finding information without having to analyze its quality. 
The Rise of Misinformation in the Digital Age

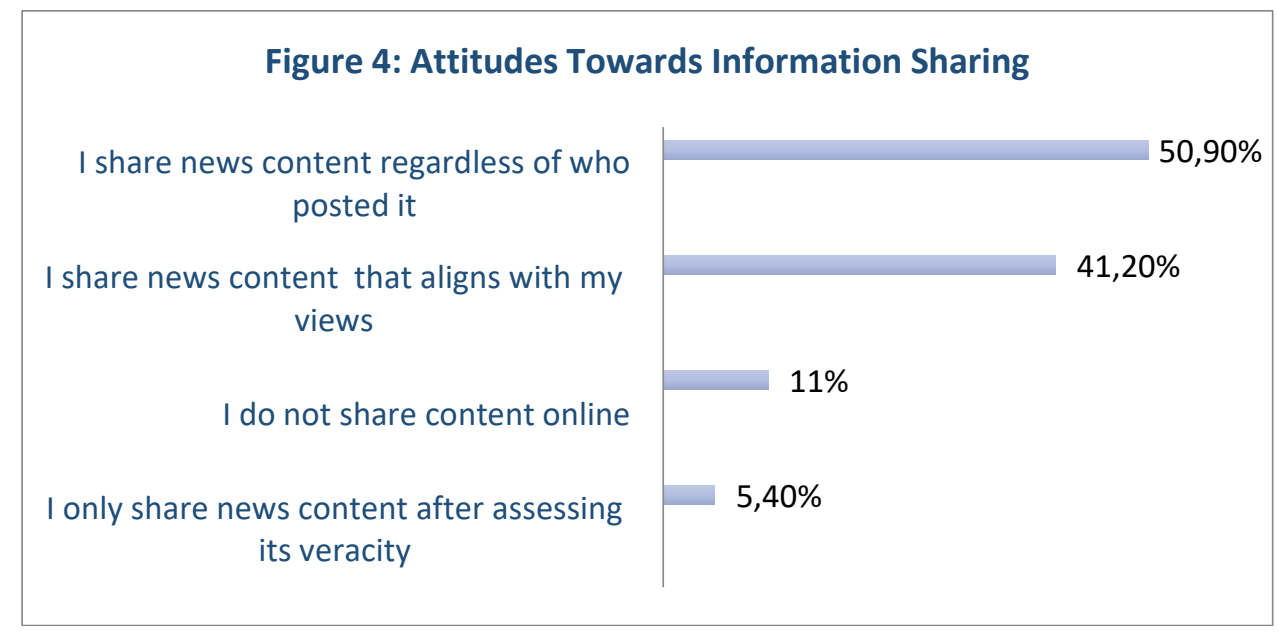

The last question of the questionnaire asked the participants to rate the extent to which EFL coursebooks currently adopted in Moroccan high schools helped develop students' digital and information literacy skills. More than three quarters reported that the coursebooks did not at all contain activities aimed at developing digital literacy and that their teachers did not devise learning activities or tasks that integrated digital literacy competences.

\section{DISCUSSION}

The findings of the present study are in accordance with the hypothesis guiding this research that a fair majority of teenage students are vulnerable to misinformation due in large to the overwhelming information overload available on the internet along with their lack of exposure to effective strategies for processing information online. The results reported here suggest that there is an increasing tendency among school students to utilize the Internet as their primary source of information. The heavy reliance on the Internet as the prime source of information may present a worry. As rightly stated by Graham and Metaxas (2014), the biggest challenge for students in this age of information overload is to evaluate the vast wealth of information available.

The findings are also in line with previous studies (Orlando, 2017; Skurski et al., 2017) showing that the growing abundance of misinformation available online that coexists alongside accurate information represents a real challenge to students unequipped with basic digital and information literacy skills. The most compelling finding is that school teens tend to absorb social media news without considering the source.

The findings showed that the surveyed teachers were cognizant of the norms of information sharing and the significance of truthfulness as a precondition for sharing information. Unlike students, teachers employed a diverse set of strategies to obtain valid information online and underscored the necessity of identifying the source from which the news was taken while reading the news online. They also postulated that social networking sites are a fertile ground for misinformation and unsubstantiated news. The surveyed teachers made it clear that their students could 
not tell the difference between fact and opinion and that they extensively used wiki sites for classroom assignments. Another interesting finding is that misinformation is liable to impact students' perception of reality and that emotionally loaded content greatly affects logical reasoning.

Unsurprisingly, the surveyed sample of teachers lacked basic training in how to develop appropriate approaches to teach digital literacy skills, particularly in empowering young learners to distinguish credible sources from unreliable ones. Accordingly, students were not exposed to any learning activities or tasks specifically aimed at enhancing digital literacy competences. Equally important, EFL textbooks in Morocco do not enable learners to build skills necessary for evaluating information. Our findings are consistent with previous studies showing that EFL textbooks in Morocco provide a small range of activities that stimulate young learners to think creatively and develop career and life-skills (Elboubekri , 2013; Bouzid, 2016).

Students lacked extensive training in digital and information literacy skills as evidenced by their inability to identify strategies employed to gauge the veracity of information online and their statement that social networking sites can serve as a credible source of information. This is further confirmed by their statement that truthfulness is not a precondition when looking for information online and their indifference towards identifying the source from which the news was taken. Another major limitation is their inability to tell the difference between fact and opinion and their excessive reliance on wiki sites for classroom assignments and school related work. As for attitudes towards information sharing, an important proportion of students reported sharing news content regardless of who posted it and irrespective of its veracity. What is also evident from the results obtained is students' lack of exposure to activities aimed at developing their digital literacy.

Secondary students show little understanding of the difference between information intended to inform and information intended to mislead or distort. This is primarily attributed to the lack of structured training and instruction on how to gauge the veracity of information circulating online (Chen \& Sin, 2013). This resonates with findings from the web survey indicating that most students cannot tell fake news from real. Students have a tendency to rely on emotion rather than reason when processing information. As such, they tend to adopt a superficial and impressionistic interpretation while processing information.

This research has shown that many young learners do not apply fact checks to the information they encounter online. As such, they seem unable to recognize bias and propaganda in media reporting. The worst-case scenario would be for young people to be seduced by extremist narratives (Bartlett \& Miller, 2011). The mounting concerns over fake news and unsubstantiated rumors have set off alarm bells among major corporations like Google and Facebook, recognizing the need to urgently address this issue. Google news introduced new measures to penalize providers of fake news. Others proposed blacklisting and blocking sources of unidentified news content (Schmidta et al, 2017). 


\section{IMPLICATIONS, RECOMMENDATIONS AND CONCLUSION}

With the proliferation of user-generated content and the affordances of media sharing functions, high school students would be easy prey for misinformation due to limited content knowledge and their lack of exposure to strategies for dealing with information online. An important finding of this study is that misinformation sharing may be largely attributed to a lack of information literacy awareness. The results obtained indicate that the vast majority of students have trouble recognizing trustworthy sources. To keep pace with the changing technological environment, it is important for students to realize that the internet is an unmonitored source of information

Valid interpretation of news stories requires knowledge of skills for evaluating and critiquing information. In today's information landscape, it is imperative for students to be critical readers of unverified claims (Tseng, 2016). To this end, schools need to identify appropriate approaches to teach the skills necessary to distinguish credible sources from unreliable ones. Teachers are called upon to help students keep up with the new, fast-moving knowledge economy, which is driven by information and technology. The basic step is to make students aware that posts should cite multiple sources, and the information should be verifiable elsewhere. As educators, we need to encourage them to read deeply before forming an opinion (Shellenbarger, 2016).

The findings derived from this case study might be of some benefit to EFL curriculum designers as well language teachers to include appropriate tasks and activities that enhance learners' critical reading skill along with critical thinking ability. A rigorous English curriculum based on a structured, explicit, and scaffolded approach to teaching critical thinking skills will better prepare high school students for college and employment (Hove, 2011). In the ever growing and evolving world of information communication technology, EFL teachers are prompted to rethink their teaching practices in ways that cope with the demands of the twenty first century skills.

As educators, we need to strive to produce well rounded individuals who can cope with the mounting challenges of this age of information overload. In a media ecology where young learners have access to vast array of numerical information, having the necessary skills and knowledge to critically assess and evaluate information is of central importance. Digital fluency must be a core competency in the National Curriculum. Schools are called upon to train pupils how to use search engines, spot propaganda techniques, identify source attribution techniques, and proofread every post before sharing it with the online world..

This study provided insight social media usage among high school students in Morocco. More specifically, it explored their attitudes and perceptions towards misinformation online. Based on findings from the web-based surveys, our study found that a significant proportion of teenage students are vulnerable to misinformation online due in large to the overwhelming information overload abundantly available online along with their lack of exposure to effective strategies for processing information online. 
The new digital age calls into question the production and dissemination of narratives online. The spreading of false and misleading narratives online raises concerns about the veracity of information and public opinion formation. As a result of the ever-increasing changes in information technology, the role of schools in preparing students for the challenges of tomorrow will be ever more important in the digital age (Kahne \& Bowyer, 2017).

\section{REFERENCES}

Anderson, J, \& Rainie, L. (2017). The Future of Truth and Misinformation Online. Pew Research Center Internet \& Technology. Retrieved from http://www.pewinternet.org/2017/10/19/the-future-of-truth-andmisinformation-online/

Bartlett, J \& Miller, C. (2011). Truth, Lies and the Internet, a Report Into Young People's Digital Fluency. Demos. Retrieved from https://www.demos.co.uk/files/Truth_-_web.pdf

Berger, J. (2014). Word of Mouth and Interpersonal Communication: A Review and Directions for Future Research. Journal of Consumer Psychology, 24(4), 586607.

Bessi A, et al. (2015) Science vs Conspiracy: Collective Narratives in the Age of Misinformation. PLoS One, 10(2): e0118093

Bessi A, Scala A, Rossi L, Zhang Q, Quattrociocchi W (2014) The Economy of Attention in the Age of (mis) Information. J Trust Manage 1(1):1-13. American Association for the Advancement of Science (AAAS). Retrieved from https://www.aaas.org /science-journals

Burgoon, J.K., Buller, D.E., Guerrero, L.K., Afifi, W.A., \& Feldman, C.M. (1996). Interpersonal Deception: XII. Information Management Dimensions Underlying Deceptive and Truthful Messages. Communication Monographs, 63(1), 52-69

Chen,X., \& Sin, S.J. (2013). Misinformation? What of it? Motivations and Individual Differences in Misinformation Sharing on Social Media. Retrieved from https://onlinelibrary.wiley.com

Donal, B. (2016). Stanford Researchers Find Students Have Trouble Judging the Credibility of Information Online. Retrieved from https://ed.stanford.edu/news/

Dong XL, et al. (2015) Knowledge-based trust: Estimating the Trustworthiness of Web Sources. Proc VLDB Endowment, 8(9): 938-949

Graham, P., \& Metaxas, T. (2014) . "Of course it's True; I saw it on the Internet!" Critical Thinking in the Internet Era. Wellesley College

Kahne, J \& Bowyer, B (2017). Educating for Democracy in a Partisan Age: Confronting the Challenges of Motivated Reasoning and Misinformation. American Educational Research Journal, 54 (1) , pp. 3 - 34.

Mrah, I. (2017). Developing Higher Order Thinking Skills: Towards a Rethinking of EFL Coursebooks in Moroccan High Schools. Journal of English Language Teaching and Linguistics, 2(3), 2017 
Orlando, J. (2017). How to Help Kids Navigate Fake News and Misinformation Online. The Conversation. Retrieved from http://theconversation.com

Schmidta, Zolloa, Vicarioa , Bessib , Scalaa,c, Caldarellia, Stanleyd , \& Quattrociocchia. (2017), Anatomy of News Consumption on Facebook. PNAS, 114 (12), 3035-3039

Shellenbarger, S. (2016, November 21). Most Students don't Know When News is Fake, Stanford Study Finds. The Wall Street Journal. Retrieved from https://www.wsj.com

Skurski,J. , Van Burnt, M. Davis, C,J \& Harrington, N (2017). Fake News: The Rise of Misinformation in the Digital Age. The Challenger. Retrieved from https://sjcawichallenger.com

Southwell, Brian G., Thorson, Emily., \& Sheble,. Laura. (2018). Misinformation and Mass Audiences. University of Texas Press

Takikawa,H, \& Nagayoshi, K. (2017). Political Polarization in Social Media: Analysis of the Twitter Political Field" in Japan, Arxiv. Retrieved from https://arxiv.org/abs/1711.06752

Tseng, A. (2016). High School Students and Critical Reading of Science Misinformation on the Internet. Students' Poster: Stanford Graduate School of Education

Zhou, L. Burgoon, J.K., Nunamaker, J.F. Jr., \& Twitchell, D. (2004). Automated Linguistics based Cues for Detecting Deception in Text-based Asynchronous Computer-mediated Communication. An Empirical Investigation. Group Decision \& Negotiation, 13(1), 81-106

\title{
Appendix A
}

\section{Informed Consent Form}

\section{Web Based Survey for Teachers}

\begin{abstract}
Introduction
The primary purpose of this survey was to gather information about the usage of social media for information seeking and sharing among high school students and to gauge their attitudes toward fake information in today's digital age. The data collected from this survey will be utilized by the researcher for purely research purposes as part of an educational research project.
\end{abstract}

Procedures

You will be kindly requested to complete a Web based survey to determine your personal attitudes towards online media content. The survey consists of 19 questions and should take you approximately less than 08 minutes to complete. The questions seek to determine the perception of Moroccan high school teachers towards information circulating on SNSs. The participants will complete an online Google survey at their own convenience.

Confidentiality

Personal data collected from participants will be treated as confidential in line with the ethics of scientific research. The data reporting results will only be presented in an aggregate format. No reference will be made to individual participants. Only the primary investigator will have access to the content of the questionnaires. All the data obtained will be safely stored in Google Forms secure 
database and will be subsequently deleted by the primary investigator immediately after executing statistical analysis and displaying results.

\section{Participation}

Moroccan high school teachers are kindly invited to respond to the questionnaire. While participation in this survey is entirely voluntary, your cooperation is critical to the success of this research study. If you choose to participate in the study, you may skip any questions that you would rather not answer.

I hereby declare that I have read and understood the contents of this informed consent agreement and agree, of my own free will, to participate in this study

Section A: Respondent profile

1 . What is your gender?
○ Male
- Female

2. How old are you?

$$
\begin{array}{ll}
\circ & 20-29 \\
\circ & 30-39 \\
\circ & 40-49 \\
\circ & 50 \text { or above }
\end{array}
$$

3. How long have you been teaching English?
- Less than 1 year
- 1-4 years
○ 5-9 years
- 10-19 years
- More than 20 years

4. Which social networking site do you use most often to obtain news?
○ Facebook
- Twitter
- WhatsApp
- YouTube
- Other

5. How many hours a day do you spend on social networking sites?
- Less than an hour
- 1-2 hours
○ 3-4 hours
- 5 or above

6. Have you ever received training in how to develop students' digital and information literacy skills?

- Yes, I have

$\circ$ No, I haven't

\section{Section B: Teachers' Attitudes towards online media content}

7. According to you, what is the most credible source of news and information?

- Social Networking sites

$\circ$ Online news sites

$\circ$ TV

- Newspapers

- Radio

- Other

8. Do you agree or disagree with the following statement? " Social networking sites are a credible source of information"
$\circ$ I strongly agree
○ Agree
- Strongly disagree
$\circ$ Disagree 
9. How do you know if what you read online is true?

10. Do you think that misinformation is liable to impact students' perception of reality?

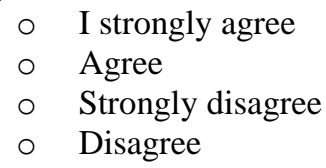

11. To what extent does emotionally loaded content affect logical reasoning?
○ To a Large Extent
- To Some Extent
- To a Small Extent
- Not at All

\section{Section C: How and for what purposes social media platforms are utilized}

12. Please rank your main reasons for using Social Media? (You can choose more than one option)

$\square$ To socialize with friends and relatives

$\square$ To gather information on educational related issues

$\square$ To keep abreast of news and developments

$\square$ To debunk rumors and false information

$\square$ To entertain and be entertained

$\square$ Other

13. Do you follow news provided by amateur/citizen journalists, professional journalists, or both?

- Amateur /Citizen journalists

- Professional journalists

○ Both of them

14. When reading an article online, which of the following strategies do you most often use to obtain legitimate information? (More than one option can be selected)
- Check that the author is real and credible
- Check that there is a valid date on the article
- Check that the story supports the headline
- Consult a fact checking site
○ Other

15. When reading the news online, do you try to identify the source from which the news was taken?
○ Yes, I do
- No, I do not
○ I don't know

16. Do you think that students can tell the difference between fact and opinion?
- Yes, they can
- No, they can't
○ I don't know

17. Do your students use wiki sites for classroom assignments?
○ Yes, they do
○ No, they don't
○ I don't know

18. Please tick the statement that best applies to you regarding information sharing
- I share news content regardless of who posted it
$\circ \quad$ I only share news content after assessing its veracity
- I share news content that aligns with my views
- I do not share content online
O Other

19. To what extend do EFL coursebooks currently adopted in Moroccan high schools help develop students' digital and information literacy skills?

- To a Large Extent

○ To Some Extent 
- To a Small Extent

- Not at All

Thank you for participating in this survey. I really appreciate you taking the time and effort to complete this survey

\section{Appendix B}

\section{Web Based Survey for Students}

Section A: Respondent profile

1. What is your gender?

○ Male

- Female

2. How old are you?

○ 14-15

○ $16-17$

- 18-19

- 20 or above

3. How many hours a day do you spend on social networking sites?

- Les than an hour

- 1-2 hours

- 3-4 hours

○ 5 hours or above

4. Which social networking site do you use most often to obtain information?
- Facebook
- Twitter
- Whatsapp
- Youtube
- Other

5. Have you ever received training on digital and information literacy skills?
- Yes, I have
- No, I haven't

Section B: Students' Attitudes towards online media content

6. According to you, what is the most credible source of information?

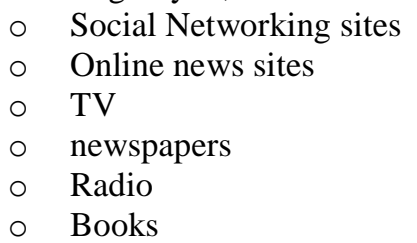

7. Do you agree or disagree with the following statement? " Social networking sites are a credible source of information"

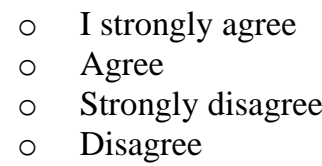

8. How do you know if what you read online is true?

9. How would you assess the impact of misinformation on people's perception of reality?
○ Strong impact
- Moderate impact
- Little impact
○ No impact 
10. Do you agree or disagree with the following statement? " The main cause behind misinformation is information overload"
$\circ \quad$ I agree
- I disagree
I don't know

Section C: How and for what purposes social media platforms are utilized

11. Please rank your main reasons for using Social Media? (You can choose more than one option)

$\square$ To socialize with friends and relatives

$\square$ To gather information on educational related issues

$\square$ To keep abreast of news and developments

$\square$ To debunk rumors and false information

$\square$ To entertain and be entertained

$\square$ Other

12. How important is truthfulness to you when sharing information on social media?
○ Very important
- Quite important
- A little important
○ Not important

13. When reading an article online, which of the following strategies do you most often use to obtain legitimate information? (More than one option can be selected)
- Check that the author is real and credible
- Check that there is a valid date on the article
- Check that the story supports the headline
- Consult a fact checking site
O Other

14. When reading the news online, do you try to identify the source from which the news was taken?
- Yes, I do
○ No, I don't

15. Can you tell the difference between fact and opinion?
- Yes, I can
- No, I can't
○ I don't know

16. Do you use wiki sites for classroom assignments?
- Yes, I do
- No, I don't

17. Please tick the statement that best applies to you regarding information sharing
- I share news content regardless of who posted it
- I only share news content after assessing its veracity
- I share news content that aligns with my views
- I do not share content online
O Other

18. When searching for information online, do you place greater emphasis on the process of finding information or on analyzing its quality?

○ The process of finding information

- The quality of the information

19. To what extend do EFL coursebooks currently adopted in Moroccan high schools help develop students' digital and information literacy skills?
○ To a Large Extent
- To Some Extent
○ To a Small Extent
- Not at All 
20. Do your teachers devise activities or tasks that help you develop your digital literacy skills?

- Yes, they do

No, they don't

- I don't know

Thank you for participating in this survey. I really appreciate you taking the time andeffort to complete this survey 